\title{
State of the Science and the Intraductal Approach for Breast Cancer: Proceedings Summary of The Sixth International Symposium on the Intraductal Approach To Breast Cancer Santa Monica, California, I9-2 I February 2009
} Susan Rochman ${ }^{1}$, Dixie Mills*1, Julian Kim² ${ }^{2}$ Henry Kuerer ${ }^{3}$ and Susan Love ${ }^{1}$

Address: ${ }^{1}$ Dr. Susan Love Research Foundation, Santa Monica, CA, USA, ${ }^{2}$ Case School of Medicine and University Hospitals, Cleveland, OH, USA and ${ }^{3} \mathrm{MD}$ Anderson Cancer Center, Houston, TX, USA

Email: Susan Rochman - Sue.rochman@earthlink.net; Dixie Mills* - dixie.mills@dslrf.org; Julian Kim - Julian.Kim@UHhospitals.org; Henry Kuerer - hkuerer@mdanderson.org; Susan Love - slove@earthlink.net

* Corresponding author

from 6th International Symposium on the Intraductal Approach to Breast Cancer Santa Monica, CA, USA. 19-21 February 2009

Published: 24 July 2009

BMC Proceedings 2009, 3(Suppl 5):II doi:10.1186/I753-656I-3-S5-II

This article is available from: http://www.biomedcentral.com/I753-656I/3/S5/II

(c) 2009 Rochman et al; licensee BioMed Central Ltd.

\begin{abstract}
Researchers are using the intraductal approach to advance breast cancer risk assessment, prevention, diagnosis, and treatment. Procedures and technologies that can access and interrogate the ductal-alveolar systems include nipple aspiration, ductal lavage and ductoscopy. Ductoscopic papillectomy, ductoscopic margin evaluation, and intraductal therapy are considered promising investigational and innovative treatments. These techniques are used to explore the biology of the normal breast; collect and analyze breast fluid and cells to identify biomarkers that can be used in breast cancer detection and risk assessment; and to identify new ways to find and administer therapeutic and/or preventive agents to the breast tissue. This report summarizes the latest research findings in these areas, presented at The $6^{\text {th }}$ International Symposium on the Intraductal Approach to Breast Cancer in 2009.
\end{abstract}

\section{Introduction}

The human breast is composed of multiple ductal lobular systems that each open onto the surface of the nipple. These ductal systems arborize into ductal trees with associated lobules and are lined with epithelial cells, where most breast cancers are thought to originate. The application of suction to the nipple openings (nipple aspiration) and ductal lavage are used to collect fluid and exfoliated cells from the breast ducts. Many substances associated with the growth, development, and tumorigeneses of the breast have been detected in breast fluids. Cytological techniques have shown that breast cancer-associated abnormalities can be found in these cells [1-6]. In addition, the production and cytological properties of nipple aspirate fluid are associated with breast cancer risk, with long-term follow-up of women undergoing nipple aspiration having shown that breast cancer risk is two to five times greater in women diagnosed with cytologic atypia than it is for women who do not yield fluid [7].

The first International Intraductal Symposium was held in 1999. A biennial event, the Symposium includes discus- 
sions and presentations on the anatomy and physiology of the normal and diseased breast, advances in intraductal technologies, findings from genetic, epigenetic, and proteomic analyses of intraductal fluid, and the latest translational research on intraductal approaches to breast cancer risk assessment, diagnoses, and treatment. The $6^{\text {th }}$ International Symposium on the Intraductal Approach to Breast Cancer, sponsored by the Dr. Susan Love Research Foundation and held in Santa Monica, California, on 19-21 February 2009, was attended by more than 100 delegates from 14 countries, including clinicians, epidemiologists, pathologists, basic scientists, translational investigators, and breast cancer advocates. The program included talks by 34 invited speakers and 16 pilot grant applicants in sessions that addressed the etiology of breast cancer; biomarkers of risk in nipple aspirate fluid and ductal lavage; anatomy, ductoscopy, and breast imaging; and intraductal therapy. Delegates also had the opportunity to attend demonstrations of ductoscopy, sonoductography, and nipple aspirate fluid collection on live volunteers.

\section{Minisymposium on a Novel Etiology for Breast Cancer: Inflammation}

The first session's speakers discussed the role that inflammation, nipple aspirate fluid and macrophages may play in breast cancer development. Lisa Coussens (University of California, San Francisco, USA) discussed her research with an MMTV-PyMT mouse model of mammary carcinogenesis that revealed a tumor-promoting role for TH2CD4 T effector cells. These novel findings suggest the immune system modulates the early onset of cancer development in specific organs, and confirmed epidemiological studies showing that increased macrophage presence correlates with higher tumor grade and decreased survival. Eliminating the T effector cells did not regulate primary disease, and also made it more likely that the cancer would metastasize to the lung, behavior that appeared to be regulated by macrophages. These findings could one day translate into an immune signature that is an independent predictor of recurrence risk, while identifying the pro-tumor mechanisms could lead to new cancer treatments.

Premalignant cell damage in the breast duct lining signals a biochemical cascade that delivers inflammatory proteins to the cell site. Chandice Covington (Texas Tech University Health Services Center, Lubbock, TX, USA) discussed one of these proteins, C-Reactive. CRP is associated with cancer risk, and has been shown to be present in increased levels in serum in more advanced breast cancer. Dr. Covington data showed that CRP levels in nipple aspirate fluid were associated with age at first pregnancy, gravidity, wean-time from breast-feeding last baby, percentage body fat, and body mass index and that CRP in NAF signifi- cantly and positively related to breast cancer risk as predicted by the Gail model.

Several large epidemiological studies have shown that non-steroidal anti-inflammatory drugs (NSAIDs) are associated with lower breast cancer risk [8]. Patricia Thompson (Arizona Cancer Center, Tucson, AZ, USA) presented data from her phase Ib dose study investigating the COX dependent and independent effect of sulindac, a non-selective NSAID with COX-independent induction of apoptosis, on NAF biomarkers. Sulindac also may affect EGFR/HER2 downstream molecules. Thirty women with increased breast cancer risk were randomized to $150 \mathrm{mg}$ or $300 \mathrm{mg}$ of sulindac daily for 6 weeks. Nipple aspiration was used to measure levels of sulindac in the breast fluid. Sulindac and sulfide were detectable in $57.7 \%$ of NAF samples with sulfone detectable in $11.6 \%$. Serum levels did not correlate with breast fluid levels. COX inhibition in the breast was achieved at $150 \mathrm{mg}$ sulindac, but the higher dose was needed to exhibit activities via COX independent pathways.

Taken together, these preliminary studies show that NSAIDs in general and COX inhibitors, in particular, could be promising agents in the prevention or early treatment of breast cancer. More attention needs to be paid to the pro- and anti-inflammatory nature of the microenvironment of the breast.

\section{Biomarkers of risk in nipple aspirate fluid and ductal lavage}

Intraductual approaches have the potential to offer new methods of assessing an individual woman's breast cancer risk. Cytology was the first method used to evaluate breast fluid for risk assessment. However, it has been shown to reveal a high degree of prognostically ambiguous atypia. These results, in conjunction with recent technological advancements, have resulted in a growing field of research aimed at identifying biomarkers in breast fluid that could be used for risk assessment as well as determining the best techniques for finding these markers in NAF.

Viruses cause several major human cancers. Gertrude Buehring (University of California, Berkeley, School of Public Health, USA), a prior pilot grant recipient, discussed her research exploring whether oncogenic viruses in NAF mammary epithelial cells can serve as biomarkers to identify women at high risk for breast cancer. She is using in situ polymerase chain reaction (PCR) to detect genomes of bovine leukemia virus, Epstein-Barr virus, and human papilloma virus. Studies have shown that all three of these viruses are found more frequently in breast tissue of women with breast cancer than they are in women with no breast cancer history [9]. 
Massimo Tommasino (International Agency for Research on Cancer, Lyon, France) presented data from his study using PCR to evaluate HPV in ductal lavage fluid. His data showed that DNA of alpha mucosa and beta cutaneous HPV types are rarely present in the breast fluids of highrisk women, suggesting that a direct role of HPV in breast carcinogenesis is unlikely.

Paul J. van Diest (University Medical Center Utrect, The Netherlands) discussed his ongoing prospective study, which has high-risk women undergo annual standard screening along with nipple aspiration. Expression of NAF was enhanced in his study with the use of nasal oxytocin spray. Quantitative multiplex methylation-specific PCR (QM-MSP) is used to identify promoter methylation of a selected set of tumor suppressor genes known to be involved in breast carcinogenesis in the NAF. "In five to ten years," said Dr. van Diest, "some of these high-risk patients will either have an operation because they have breast cancer or decide to have a prophylactic mastectomy, which would permit us to compare methylation data with what is found in surgical tissue to determine if there is a correlation between the number of methylated genes that are present and risk."

Proteomic profiling may have more value for risk assessment than as a diagnostic screening tool. Savitri Krishnamurthy (MD Anderson Cancer Center, Houston, TX, USA) discussed her research that is using an array of techniques, including ELISA, high-resolution proteomic analysis, SELDI-TOF, and protein microarrays to identify protein signatures in NAF that could be used for risk assessment. The seven proteins her team is currently investigating include insulin-like growth-factor binding protein-3, basic fibroblast growth factor, CRP, erythropoietin, urokinase and prostaglandin E2.

Ercole Cavalieri, (Eppley Institute for Research in Cancer and Allied Diseases, University of Nebraska Medical Center, Omaha, NE, USA) discussed his research on DNA adducts, which play a major role in cancer development. Estrogen-purine DNA adducts are shed from cells and end up in the blood and urine. His studies have shown that high levels of estrogen-DNA adducts are associated with breast cancer risk. He noted that "since the reaction of catechol estrogen quinones with DNA is the first critical step in the initiation of cancers, elimination of DNA adduct formation should block the initiation and development of cancer," this may be a new target for breast cancer prevention and treatment.

Robert Chatterton (Feinberg School of Medicine, Northwestern University, Chicago, IL, USA) presented data from a study investigating the endocrine environment of the breast. Forty-seven premenopausal and 40 postmenopau- sal high-risk women underwent ductal lavage and NAF collection and also provided a serum sample. Those at high risk were offered tamoxifen as a chemopreventative agent and a repeat ductal lavage 6 months later. The results showed that NAF and ductal lavage fluid contain a rich source of hormones and other markers of risk, but the findings are too preliminary to draw any conclusions.

Ferdinando Mannello (University "Carlo Bo," Urbino, Italy), a prior pilot grant recipient, presented an update on his research study investigating the role oxidative stress plays in the breast microenvironment and the function of adhesion molecules in the breast cells of the ductal-lobular unit. He has published his findings on protein analyses of NAF in healthy women versus breast cancer patients [10].

Catharina Svanborg (Lund University, Sweden) is studying HAMLET (human a-lactalbumin made lethal to tumor cells), a protein-lipid complex that is found in human milk, and that shows promise as a new anti-cancer agent. HAMLET kills tumor cells and immature cells but spares healthy differentiated leukocytes. HAMLET shows broad anti-tumor activity, and Dr. Svanborg's studies have identified several death pathways activated by HAMLET in tumor cells, including apoptosis, anoikis, and autophagy [11].

Hypermethylated genes are promising powerful biomarkers of breast cancer detection and perhaps risk assessment. Studies have shown that tumor suppressor gene (TSG) methylation is identified more frequently in random periareolar fine needle aspiration samples from women at high risk for breast cancer than in women at low risk. David Euhus (University of Texas Southwestern Medical Center, Dallas, TX) investigated whether the finding that would hold true for breast fluid samples obtained via ductal lavage. For this study, 514 samples obtained from 150 women were assessed cytologically and by Quantitative Multiplex Methylation-Specific PCR (QM-MSP) for methylation of cyclin D2, APC, HIN1, RASSF1A, and RARbeta2. Dr. Euhus reported that the study showed that TSG methylation in ductal lavage samples did not predict marked atypia, and that both methylation and marked atypia were independently associated with highly cellular samples, Gail model risk, and a personal history of breast cancer, suggesting related, but independent, pathogenic pathways in breast epithelium [12].

Mary Jo Fackler (Johns Hopkins University School of Medicine, Baltimore, MD, USA) is also using QM-MSP to identify potential biomarkers. Dr. Fackler presented findings from a pilot study that explored the potential of using ductoscopic washings along with QM-MSP to evaluate spontaneous nipple discharge and that showed that QM- 
MSP is 3-fold more sensitive than cytology in identifying cancerous cells. She also discussed a prospective pilot study of 54 postmenopausal women who were receiving anastozole as their sole adjuvant therapy. Thirty-three of the women had an optional contralateral biopsy at baseline and at 6 months after starting treatment. A comparison of these biopsy samples showed significant decreases in methylation for TWIST1, RASSF1A, and RARbeta. Both findings suggest more prospective studies are necessary to evaluate the relationship between changes in methylation and breast cancer incidence.

Gerald Gui (Royal Marsden Hospital, London, UK) presented data from his study comparing measurements of methylation-specific PCR in ductal lavage fluid, breast cancer tissue, adjacent normal breast parenchyma, and plasma in women with early breast cancer. The study showed a positive correlation between tumor tissue and ipsilateral ductal lavage in women with breast cancer $(\mathrm{n}=$ 24). Methylation was also significantly higher in tumor and ipsilateral ductal lavage fluid when compared with adjacent normal tissue and contralateral ductal lavage.

Bassem Haddad (Georgetown University, Washington, DC, USA) discussed his research aimed at identifying a panel of biomarkers that could improve the diagnostic value of ductal fluid in detecting pre-malignant breast lesions and early stages of breast cancer in high-risk women. Edward Sauter (University of North Dakota School of Medicine, Grand Forks, ND, USA) discussed his use of two intraductal approaches, ductoscopy and nipple aspiration, to assess response to both pharmacologic and nutritional chemopreventive interventions.

Catherine Carpenter (University of California, Los Angeles, USA), a prior pilot grant recipient, provided an update on her research investigating the impact of diet and exercise on biomarkers in breast ductal fluid in overweight postmenopausal women. To date, five previously sedentary overweight women have completed the study. Preliminary midpoint data showed a major drop in leptin, DHEA, and estrone in serum that was not mirrored in the lavage fluid.

The Gail Risk model, which is widely used to assess breast cancer risk, was developed based on data from Caucasian women and has been found to be less accurate in assessing risk in women of other ethnicities [13]. Lisa Bailey (Carol Ann Read Breast Health Center, Alta Bates Summit Medical Center, Oakland, CA, USA), a prior pilot grant recipient, provided an update on her research exploring the feasibility of an intraductal approach for risk assessment in African American, Asian, and Hispanic women.
Atilla Soran (Magee-Womens Hospital, University of Pittsburgh Medical Center, PA, USA), a prior pilot grant recipient, presented preliminary research findings from his study investigating anti-MUC1 and anti-cyclin B1 antibodies in nipple aspirate fluid in breast cancer patients. He suggested that more sensitive techniques for antibody detection might be needed to identify the low antibody levels in the premalignant lesions, which could boost the usefulness of NAF as the source for this diagnostic assay.

These presentations demonstrated the different types of strategies researchers are using to identify biomarkers associated with genetic, epigenetic, and proteomic abnormalities in breast fluid. These reports add to growing body of published studies that have found that biomarkers appear to be more sensitive than cytologic atypia in predicting breast cancer risk. [14-22]

\section{Anatomy, ductoscopy, and imaging of the breast} Intraductal approaches have been used to advance our understanding of the anatomy of the breast. They have provided evidence that the breast ducts do not form an even, radial pattern, and shown us that there are both central ducts that go directly back to the chest wall and peripheral ducts that drape over this central group. This knowledge of the anatomy of human breast will guide future breast cancer research. Intraductal approaches are also utilized in the intraoperative setting in patients with both benign and malignant breast conditions to guide treatment decisions. As James Going (University of Glasgow, Scotland, UK), a prior pilot grant recipient, underscored in his presentation, "Anatomy seems oldfashioned, but a house without a good foundation is a rickety structure and we need to understand that foundation, no matter how good the biology."

Dr. Going's presented findings from his research investigating what he calls "the paradox of nipple anatomy." As he noted, 5-9 ostia can be observed in the lactating breast, and a few of these ostia can be cannulated. Yet 20-30 ducts are observed when the nipple is transected raising the question, "What are these ducts doing?" He found no evidence for his previous two-duct-type hypothesis, but did find evidence that appears to point to ostium sharing - several ducts converging in a common opening in the nipple.

Gerald Gui (Royal Marsden Hospital, London, UK) reported findings from his study investigating the anatomical association between fluid yielding ducts and breast cancer location. This study of 40 patients undergoing mastectomy for breast cancer, used ductal lavage followed by infusion of the mastectomy specimens ex vivo with a colored resin. It showed that the duct system of the cancer affected segment was concordant to a fluid-yield- 
ing duct in $58 \%$ of cases, a similar finding to previous studies. Dr. Gui said this suggested that cytology studies would likely be limited by duct accessibility whereas protein studies, which could demonstrate a field effect, would not.

Sheldon Feldman (Columbia University New York City, NY, USA) provided a history and overview of the field of mammary ductoscopy. The ability to see ductal pathology and monitor response to therapy in real time along with technological improvements, including better visualization and an interventional approach, are moving the field forward. Current challenges include the absence of an established CPT code and a lack of data from clinical trials evaluating the efficacy and clinical role of ductoscopy or randomized trials evaluating whether more cancers are found with ductoscopy. Even so, said Dr. Feldman, "We are on the threshold of the future."

Fatih Balci (Ankara State Hospital, Ankara, Turkey) presented images and data from his study evaluating the therapeutic value of endoscopic papillectomy in patients with pathologic nipple discharge (PND). Breast ductoscopy was performed on 178 of 213 patients with PND enrolled in the study. All visualized papillomas were removed endoscopically with a scope with a grasping basket. Dr. Balci reported that they identified 34 papillomas and 5 cases of DCIS, and that there was a $100 \%$ correlation between ductoscopy findings and histopathology. These findings, said Dr. Balci, confirm that ductoscopic papillectomy "is a safe and easy procedure to remove intraductal papillomas from the breast that avoids unnecessary resection of breast tissue" [23].

William Dooley (University of Oklahoma, Oklahoma City, OK, USA) discussed current techniques and uses for ductoscopy. In his clinical practice, Dr. Dooley routinely uses ductoscopy to manage early invasive cancer. As a result, he said, he has a low annual hazard rate for ipsilateral breast cancer recurrence. In the discussion that followed, Dr. Dooley noted that surgeons rely on radiation to improve local control, but that ductoscopy could do the same. "If we can get good enough at doing endoscopically directed lumpectomy," he said, "we would not need to perform radiation unless there was lymphovascular invasion." One essential area needed to advance the field of ductoscopy will be carefully planned prospective multicenter studies to address the sensitivity, specificity, false negative and false positive rates of ductoscopy in accurately identifying cancerous versus non-cancerous tissue.

Wai-ka Hung (Kwong Hospital, Kowloon, Hong Kong) discussed the role of mammary ductoscopy in breast surgery, also noting that for the field to move forward good endoscopic-pathologic correlation was necessary. This, in turn, could spare women unnecessary surgery, as it would allow for therapeutic mammary ductoscopy and removal or ablation of a papilloma. In addition, if it could be determined that there was no ductal involvement in the areola, it might also be used to better select appropriate candidates for for nipple-sparing mastectomy.

Debra Strick (University of California, Los Angeles, USA), a prior pilot grant recipient, presented findings from her research on intraductal micromagnetic resonance imaging and spectroscopy. Dr. Strick developed an intraductal radiofrequency microcoil that can reduce the volume of diseased tissue to a cubic-centimeter, allowing MRI spectroscopy, which could distinguish between benign and malignant tissue, and therefore be used for early diagnosis. This microcoil could potentially be used with ductoscopy and conventional MRI to reduce false-positives or for an MRI-guided biopsy.

\section{Intraductal therapy: background, current and future}

The session on intraductal therapy highlighted studies investigating preclinical testing and early phase human clinical trials.

Dixie Mills (Dr. Susan Love Research Foundation, Santa Monica, CA, USA) presented data from a study exploring the physiology of the resting, or non-lactating, breast. A total of 14 women underwent blood collection, nipple aspiration, and ductal lavage five times over 12 hours. After baseline testing, subjects were given $200 \mathrm{mg}$ of caffeine (NoDoz) and $200 \mathrm{mg}$ of cimetidine (Tagamet). Previous studies have shown that in lactating women caffeine passively diffuses into milk rapidly and reflects serum levels. This study found that in the resting breast, caffeine levels peaked at 6 hours or later. Cimetidine has previously been found to be concentrated in the milk of lactating women, but was not detected in the ductal fluid obtained from the resting breast. These findings reinforce the need for more studies on the resting breast as its properties are clearly different than the lactating breast.

Saraswati Sukumar (The Sidney Kimmel Comprehensive Cancer Center, Johns Hopkins University, Baltimore, MD, USA) presented new data from her preclinical studies with pegylated liposomal doxorubicin (PLD) in rat and mouse models of breast cancer. Dr. Sukumar reported that in addition to preventing tumor formation for three months or more, PLD appeared to stunt the growth of the mammary glands in mice. Following up on this finding, she looked at the response of the treated mammary gland to a new pregnancy. She reported that that pups were unable to get sufficient milk from the treated duct, suggesting a compromised response in the mammary gland to pregnancy hormones. In addition, pregnancy did not increase 
the incidence of tumors in PLD treated mice. She also noted that their studies have found that mice receiving intraductal treatment have fewer stem cells than other mice, which has resulted in a new line of investigation [24].

Moving into the clinic setting, Vered Stearns (Johns Hopkins School of Medicine, Baltimore, MD, USA) presented data from a phase I feasibility study of PLD in women awaiting mastectomy. Participants underwent nipple aspiration and ductal cannulation using a dose escalation scheme. Blue dye was injected into the treated duct just prior to mastectomy and tissue was obtained for pharmacokinetic and biomarker analysis. Dr. Stearns reported that doxil was present in the region at both the $5 \mathrm{mg}$ and $10 \mathrm{mg}$ dose, evidence that it can leave the duct. No changes were seen in the stroma surrounding the ducts, however a dose-dependent effect was seen in plasma and in breast tissue. Noting that there is no data on how IV doxil affects breast tissue, Dr. Stearns said her next study would compare the breast tissue of women who receive IV doxil prior to surgery with that of women receiving intraductal doxil.

Susan Love (Dr. Susan Love Research Foundation, Santa Monica, CA, USA) presented data from a Phase I feasibility study conducted in Beijing, China. One of two drugs, PLD or carboplatin, were used intraductally 2-7 days prior to mastectomy, at 3 dose levels, with the highest dose approximating the clinical intravenous dose. Dr. Love reported that PLD stayed in the duct longer and showed a lower serum dosage. At the highest doses, women receiving PLD reported tenderness and erethyma, whereas the highest doses of carboplatin resulted in mild nausea and vomiting, a sign that the drug had gotten into the bloodstream. Dr. Love also reported that pathological examination showed the drugs were widely distributed through the ductal systems reaching the terminal duct lobular units. In conclusion, said Dr. Love, this shows us that this approach is feasible and safe.

Jianyu Rao (David Geffen School of Medicine, University of California, Los Angeles, USA) described the histopathological changes observed in the study Dr. Love presented. The pathology was not performed to study the tumor but to assess ductal epithelial cell changes and inflammatory reaction seen in ducts and surrounding fibroadipose tissue in association with duct treatment. Dr. Rao reported that carboplatin resulted in a dose-response increase of both in inflammation and ductal epithelial cell changes. In contrast, PLD resulted in no severe inflammatory changes in any dose group, but there was a significant increase of epithelial response. Dr. Rao said this suggests that short-term intraductal treatment may induce some degree of epithelial changes and some inflammatory response, while the long-term effect remains to be determined.

Ellen Mahoney (St. Joseph Hospital, Eureka, CA, USA) presented data from her pilot preoperative study testing the effects of PLD delivered through the affected duct of 30 women with DCIS diagnosed by core needle biopsy awaiting surgery. To date, six patients have undergone treatment. In those who were treated successfully with PLD, the pathology has revealed reactive and reparative changes to the duct. If this proves effective, said Dr. Mahoney, we could develop "a chemical mastectomy for post-breastfeeding women that would eradicate the stem cells and epithelial cells inside the breast duct, thus eliminating the possibility for breast cancer to occur."

Taken together, the intraductal approach for potential prevention and therapy of breast cancer has been born and is growing as more researchers begin to study and answer the critical questions needed to advance this exciting emerging field.

\section{Pilot grants}

The Dr. Susan Love Research Foundation utilizes a unique grant review mechanism to distribute pilot grants at the Symposium. Applicants submit one-page abstracts and responsive proposals are selected for presentation at the meeting. A multidisciplinary peer review committee, comprised of basic scientists, breast cancer activists, and physicians, evaluates both the abstracts and the presentations. At the Symposium, 16 researchers presented proposals. At the close of the Symposium, the Foundation announced that it would be providing $\$ 84,000$ to support 8 innovative research projects utilizing the intraductal approach.

The 2009 recipients were: Robert Chatterton, PhD, and Seema Khan, PhD (Northwestern University), 'Investigation of factors regulating estrogen uptake and retention by the breast'; Hong Ling, MD (Cancer Institute, Fudan University), 'Comparison of $\mathrm{PH}$ value in nipple aspiration fluid from ductal carcinoma with or without calcification'; Ferdinando Mannello, PhD, and Gaetana Tonti, PhD (University of Urbino 'Carlo Bo'), 'Iron-driven inflammation in the breast microenvironment: assessment of ironoverload in breast cancer development'; Atilla Soran, MD (University of Pittsburgh Medical Center), 'Autoflourescence ductoscopy for the early detection of breast cancer'; Barbara Urban, MD, and Lorriaine Tafra, MD (Anne Arundel Breast Center), 'Pilot study to identify breast cancer protein biomarkers in nipple aspirate fluid'; Ameae Walker, PhD (University of California, Riverside), 'A prolactin binding compound in breast ductal fluids';

Daniel Wreschner, MD (Tel-Aviv University), 'Monoclonal antibodies and peptides targeting the MUC1 alpha/ 
beta junction of the ablation of human cancer cells via the intraductal approach'; Gang Zeng, PhD (University of California, Los Angeles), 'A multiplex approach for detecting antibodies in the nipple fluid of breast cancer patients'.

\section{Conclusion}

The $6^{\text {th }}$ International Symposium on the Intraductal Approach to Breast Cancer highlighted the advances that have made in intraductal research and the potential the intraductal approach has to change clinical practice. Delegates in attendance expressed an interest in designing collaborative studies that can provide more data on the effectiveness of ductoscopy and identify new biomarkers in breast fluid. An update on these projects, along with findings from this year's pilot grant projects, will be presented in 2011 at the $7^{\text {th }}$ International Symposium on the Intraductal Approach to Breast Cancer.

\section{List of abbreviations used}

CRP: C-reactive protein; DCIS: ductal carcinoma in-situ; NAF: Nipple aspirate fluid; PLD: Pegylated liposomal doxorubicin; PND: pathologic nipple discharge; QM-MSP: Quantitative multiplex, methylation-specific polymerase chain reaction; PCR: polymerase chain reaction.

\section{Competing interests}

Susan Love is a founder, Board member and share holder of Brexys (Windy Hill Medical).

\section{Acknowledgements}

This conference was supported in part by the Avon Foundation, American Cancer Society, California Breast Cancer Research Foundation, $\mathrm{NCl}$ - Division of Cancer Prevention, NeoMatrix, LLC, Office of Research on Women's Health, NIH, PolyDiagnost GmbH, Windy Hill Medical, Inc. We would like to thank Ashley Casano and Insiyah Nomanbhoy for their assistance on this publication.

This article has been published as part of BMC Proceedings Volume 3 Supplement 5, 2009: 6th International Symposium on the Intraductal Approach to Breast Cancer. The full contents of the supplement are available online at http://www.biomedcentral.com//753-656I/3? issue=S5.

\section{References}

I. Papanicolaou GN, Holmquist DG, Bader GM, Falk EA: Exfoliative cytology of the human mammary gland and its value in the diagnosis of cancer and other diseases of the breast. Cancer 1958, I I:377-409.

2. Petrakis NL, Mason L, Lee R, Sugimoto B, Pawson S, Catchpool F: Association of race, age, menopausal status, and cerumen type with breast fluid secretion in nonlactating women, as determined by nipple aspiration. J Natl Cancer Inst 1975, 54:829-834.

3. Sartorius OW, Smith HS, Morris P, Benedict D, Friesen L: Cytologic evaluation of breast fluid in the detection of breast disease. J Natl Cancer Inst 1977, 59: 1073-1080.

4. Rose DP, Lahti H, Laakso K, Kettunen K, Wynder EL: Serum and breast duct fluid prolactin and estrogen levels in healthy Finnish and American women and patients with fibrocystic disease. Cancer 1986, 57:| 550-|554.

5. Wrensch MR, Petrakis NL, King EB, Miike R, Mason L, Chew KL, Lee MM, Ernster VL, Hilton JF, Schweitzer R, et al.: Breast cancer inci- dence in women with abnormal cytology in nipple aspirates of breast fluid. Am J Epidemiol 1992, 135:130-141.

6. Buehring GC: Screening for breast atypias using exfoliative cytology. Cancer 1979, 43:1788-1799.

7. Wrensch MR, Petrakis NL, Miike R, King EB, Chew K, Neuhaus J, Lee $M M$, Rhys M: Breast cancer risk in women with abnormal cytology in nipple aspirates of breast fluid. J Natl Cancer Inst 200I, 93:179I-1798. doi: 10.1093/jnci/93.23.1791.

8. Agrawal A, Fentiman IS: NSAIDs and breast cancer: a possible prevention and treatment strategy. Int J Clin Pract 62(3):444-9.

9. Lawson JS, Günzburg WH, Whitaker NJ: Viruses and human breast cancer. Future Microbiol 2006, I:33-5I.

10. Mannello F, Medda V, Tonti GA: Protein profile ana lysis of the breast microenvironment to differentiate healthy women from breast cancer patients. Expert Rev Proteomics 2009, 6(I):43-60.

II. Gustafsson L, Aits S, Onnerfjord P, Trulsson M, Storm P, Svanborg C: Changes in proteasome structure and function caused by HAMLET in tumor cells. PLoS ONE 2009, 4(4):e5229.

12. Euhus DM, Bu D, Milchgrub S, Xie XJ, Bian A, Leitch AM, Lewis CM: DNA methylation in benign breast epithelium in relation to age and breast cancer risk. Cancer Epidemiol Biomarkers Prev 2008, |7(5): $105 \mid-9$.

13. Tice JA, Cummings SR, Ziv E, Kerlikowske K: Mammographic breast density and the Gail model for breast cancer risk prediction in a screening population. Breast Cancer Res Treat 2005, 94(2): $115-22$.

14. King BL, Tsai SC, Gryga ME, D'Aquila TG, Seelig SA, Morrison LE, Jacobson KK, Legator MS, Ward DC, Rimm DL, et al.: Detection of chromosomal instability in paired breast surgery and ductal lavage specimens by interphase fluorescence in situ hybridization. Clin Cancer Res 2003, 9:1509-1516.

15. Krishnamurthy S, Zhao L, Hayes K, Glassman AB, Cristofanilli M, Singletary SE, Hunt KK, Kuerer HM, Sneige N: Feasibility and utility of using chromosomal aneusomy to further define the cytologic categories in nipple aspirate fluid specimens: a preliminary study. Cancer 2004, 102:322-327. doi: 10.1002/cncr.20558.

16. Evron E, Dooley WC, Umbricht CB, Rosenthal D, Sacchi N, Gabrielson $E$, Soito AB, Hung DT, Ljung B, Davidson NE, et al.: Detection of breast cancer cells in ductal lavage fluid by methylationspecific PCR. Lancet 200I, 357:1335-I336. doi: I0.1016/SOI406736(00)0450I-3.

17. Krassenstein R, Sauter E, Dulaimi E, Battagli C, Ehya H, Klein-Szanto $A$, Cairns P: Detection of breast cancer in nipple aspirate fluid by CpG island hypermethylation. Clin Cancer Res 2004, 10:28-32.

18. Fackler MJ, McVeigh M, Mehrotra J, Blum MA, Lange J, Lapides A, Garrett E, Argani P, Sukumar S: Quantitative multiplex methylationspecific PCR assay for the detection of promoter hypermethylation in multiple genes in breast cancer. Cancer Res 2004, 64:4442-4452.

19. Zhu W, Qin W, Ehya H, Lininger J, Sauter E: Microsatellite changes in nipple aspirate fluid and breast tissue from women with breast carcinoma or its precursors. Clin Cancer Res 2003, 9:3029-3033.

20. Isaacs C, Cavalli LR, Cohen Y, Pennanen M, Shankar LK, Freedman M, Singh B, Liu M, Gallagher A, Rone JD, et al.: Detection of LOH and mitochondrial DNA alterations in ductal lavage and nipple aspirate fluids from high-risk patients. Breast Cancer Res Treat 2004, 84:99-105. doi: 10.1023/B:BREA.0000018406.03679.2e.

21. Zhu W, Qin W, Bradley P, Wessel A, Puckett CL, Sauter ER: Mitochondrial DNA mutations in breast cancer tissue and in matched nipple aspirate fluid. Carcinogenesis 2005, 26:145-152. doi: 10.1093/carcin/bgh282.

22. Yamamoto D, Senzaki H, Nakagawa H, Okugawa H, Gondo H, Tanaka K: Detection of chromosomal aneusomy by fluorescence in situ hybridization for patients with nipple discharge. Cancer 2003, 97:690-694. doi: 10.1002/cncr.I 1091 .

23. Bender O, Balci FL, Yüney E, Akbulut H: Scarless endoscopic papillomectomy of the breast. Onkologie 2009, 32(3):94-8.

24. Murata S, Kominsky SL, Vali M, Zhang Z, Garrett-Mayer E, Korz D, Huso D, Baker SD, Barber J, Jaffee E, Reilly RT, Sukumar S: Ductal access for prevention and therapy of mammary tumors. Cancer Res 2006, 66(2):638-45. 